\title{
In vitro Plant Propagation and Crop Improvement in Lisianthus (Lisianthus russelianus Hook.)
}

\author{
Rodica POP${ }^{1}$, Maria CANTOR ${ }^{1 *}$, Erzsebet BUTA ${ }^{1}$, Iudita CSETE ${ }^{1}$ \\ ${ }^{1}$ Department of Horticulture, University of Agricultural Sciences and Veterinary Medicine Cluj-Napoca, \\ Romania \\ *)Corresponding author, e-mail: marcantor@yahoo.com
}

BulletinUASVM Horticulture 73(2) / 2016

Print ISSN 1843-5254, Electronic ISSN 1843-5394

DOI:10.15835/buasvmcn-hort:12367

\begin{abstract}
Romania assists at the present time to an increase of production crops for ornamental plants and as a consequence an increased demand of planting material. Thus, improvements of the current multiplication methods are sought after. Lisianthus russelianus Hook. (Eustoma grandiflorum Grise.) is a relatively new floral crop to the international market, known for beautiful flowers of various colors and for having a long vase life. This study focused on the development of an efficient protocol for rapid regeneration of this species following known basic and applied aspects of lisianthus biotechnology but exploring new potentials. In the course of experiments conducted, for in vitro multiplication there were used nodal segments $(1.5 \mathrm{~cm})$ with axillary buds from three $\mathrm{F}_{1}$ hybrids 'Echo Lavender', 'Flamenco White', 'Mirage Pastel Pink' that were inoculated on MS basal medium supplemented with $0.50 \mathrm{mg} 1^{-1} \mathrm{TDZ}, 1.0 \mathrm{mg} 1^{-1} \mathrm{BAP}$ and $0.50 \mathrm{mg} 1^{-1} \mathrm{AIA}$. The results show that the medium with BAP was most effective for obtaining the highest shoots number compared to medium containing TDZ. For rooting induction, two different concentrations of auxin IBA $0.5 \mathrm{mg}^{-1}$ and $1.5 \mathrm{mg}^{-1}$ were used simultaneously on MS basal medium. The highest roots number occurred when using $1.5 \mathrm{mg}^{-1}$ IBA. Both the number of shoots and rooting regeneration were dependent on the cultivar. The highest shoots number was achieved for 'Mirage Pastel Pink' hybrid (6.91) on the medium containing $1.0 \mathrm{mg}^{-1} \mathrm{BAP}$ and $0.50 \mathrm{mg}^{-1} \mathrm{IAA}$.
\end{abstract}

Keywords: cytokinin, Eustoma grandiflorum, hybrids, vegetative propagation

\section{INTRODUCTION}

Lisianthus (Eustoma grandiflorum Grise.) is a herbaceous annual or biennial ornamental plant with beautiful flowers slightly resembling roses. The species belongs to Gentianaceae family, and the present cultivated plants were derived from an American wildflower that is native to the North American prairies all the way from Colorado to Nebraska and down to Texas. Lisianthus experienced a spectacular ascension in the floricultural assortment in recent decades both as cut flower as well as potted plant. This fast expansion on flower markets was due to its unmatched qualities such as color of flowers, long vase life, and the possibility of obtaining productions all year round (Toma,
2009). Older authors like Hecht et al. (1994), noted more than two decades ago that lisianthus was already well known for its long vase life, size, and different colors of its flowers.

In Romania Lisianthus was introduced in 1980 at Codlea Brasov in greenhouse production (Toma, 2009) but nowadays the assortment is very limited despite the fact that on the international market it is recognized as one of the top 10 cut flowers in the world (Esizad et al., 2012).

The breeders in the recent times have developed a variety of hybrids and cultivars with many superior characteristics such as larger blooms in a wide color range, as well as double flowers, heat tolerance, different flower shape 
and size, disease resistance, lack of rosetting etc. (Harbaugh, 2006).

Eustoma grandiflorum is propagated by conventional methods: generative by seeds and vegetative by cuttings. Propagation by seeds shows a wide range of variation for certain traits due to their heterozygous character (Furukawa et al., 1990), also the germination rate is low at $34-39 \%$ (Winarto et al. 2015). In vitro propagation can be effectively used for rapid multiplication and as explant are often used: stems, axillary buds, leaves and meristems in order to obtain homogenious material for increased high-quality yields in large scale production. However, some authors (Rezaee et al., 2012) showed that among different lisianthus plant parts, leaf explants were best for obtaining callus, while the lowest percentage of callus was emerged from internodal stem explants.

The methods for micropropagation of Lisianthus grandiflorum have been developed or perfected by many researchers throughout time such as Semeniyuk and Griesbach (1987), Furukawa et al. (1990), Paek and Hahn (2000), Jain et al. (2010), Mousavi et al. (2012), Rezaee et al. (2012), Akabari et al. (2014), Kaviani et al. (2014), and Winarto et al. (2015) and others. Thus, various researches conducted in the past have led to the development of increasingly efficient protocols for the rapid regeneration and in vitro multiplication of this species. Some studies indicated that from several culture media used, the basal MS medium containing $3 \mathrm{mg} 1^{-1} \mathrm{IAA}, 3 \mathrm{mg}^{-1} \mathrm{NAA}, 0.1 \mathrm{mg} 1^{-1}$ kinetin, and B5 medium containing $0.225 \mathrm{mg}^{-1} \mathrm{BA}$ and 1.86 mg $1^{-1}$ NAA were the best media for induction of callus in lisianthus (Rezaee et al., 2012).

The objective of the present study was aimed to investigate further the efficiency of different medium composition and growth regulators for in vitro multiplication of Eustoma grandiflorum and obtain results that would enable researchers to identify the best type of medium for this species.

\section{MATERIALS AND METHODS}

The biologic material used in the experiments, was comprised of three $\mathrm{F}_{1}$ hybrids of lisianthus (Lisianthus russelianus Hook, syn. Eustoma grandiflorum Grise) as follows: 'Echo Lavender', 'Flamenco White' and 'Mirage Pastel Pink'. The seeds obtained from Sakata Company were sown in controlled conditions in the greenhouse at the USAMV Cluj-Napoca. After three months the seedlings obtained were used as source for explants. Nodal segments $(1.5 \mathrm{~cm})$ with axillary buds were excised from these seedlings to be used for in vitro propagation.

These explants were first washed in running tap water for 30 minutes. Then, the excised nodal explants were treated with $2 \%(\mathrm{v} / \mathrm{v})$ sodium hypochlorite $(\mathrm{NaOCl})$ and 2-3 drops Tween 20 for 20 minutes in a laminar air flow chamber. Next, the explants were three times rinsed in double distilled sterile water (ten minutes each). The explants were cultured on the MS medium (Murashige and Skoog, 1962) in two variants:

$\mathrm{V}_{1}-\mathrm{MS}+0.50 \mathrm{mg}^{-1}$ TDZ (N-phenil-N'-1,2,3thidiazol-5-yl urea) $+0.50 \mathrm{mg} 1^{-1}$ IAA (indoleacetic-acid);

$\mathrm{V}_{2}$ - MS + $1.00 \mathrm{mg}^{-1} \mathrm{BAP}$ (6-benzyl aminopurine) $+0.50 \mathrm{mg}^{-1}$ IAA.

In the current study the effect of IBA (indole3-butyric-acid) in a concentration of 0.5 and 1.5 mg 1-1 on MS medium was evaluated to determine the rooting of regenerated shoots.

The medium of all variants was improved with $3 \%$ sucrose, $0.65 \%$ agar. The medium $\mathrm{pH}$ value was set between 5.7-5.8 prior to autoclaving (20 min. at $121^{\circ} \mathrm{C}$ and $\left.1 \mathrm{~atm}\right)$. A growing chamber was utilized for culture incubation at a temperature of $22 \pm 2^{\circ} \mathrm{C}$ and $16 / 8$ hours photoperiod. The light intensity of 2500-3000 lux was provided by cool-white fluorescent lamps. Every 4 weeks subcultures were carried out.

In order to acclimatize the rooted plantlets plastic pots containing peat were utilized. To assure high humidity the plantlets were covered with polyethylene bags for two weeks. Acclimatized plants were transferred into greenhouse conditions.

For each variant, 30 explants were analyzed and three replications were made. The data obtained was subsequently analyzed using analysis of characteristics variance (SPSS Inc. Chicago, IL, USA) for bifactorial experiments ( $3 \times 2$ ) and means were evaluated by Duncan test ( $5 \%$ level).

\section{RESULTS AND DISCUSSION Proliferation}

The results of this experiment showed that the concentration, the type of cytokinins and hybrids used significantly influenced the number and length of shoots. 
Tab.1. Effects of culture medium $(\mathrm{M})$, hybrid $(\mathrm{H})$ and the interaction $(\mathrm{M} \times \mathrm{H})$ upon the numbers of shoots of micropropagated Lisianthus

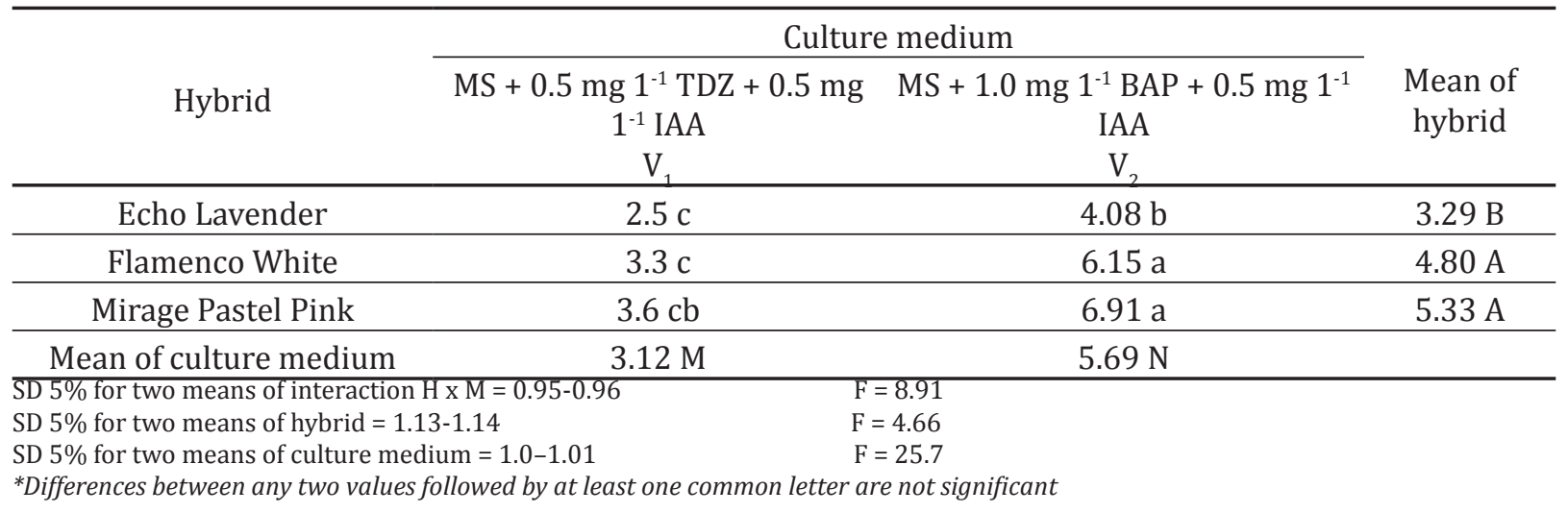

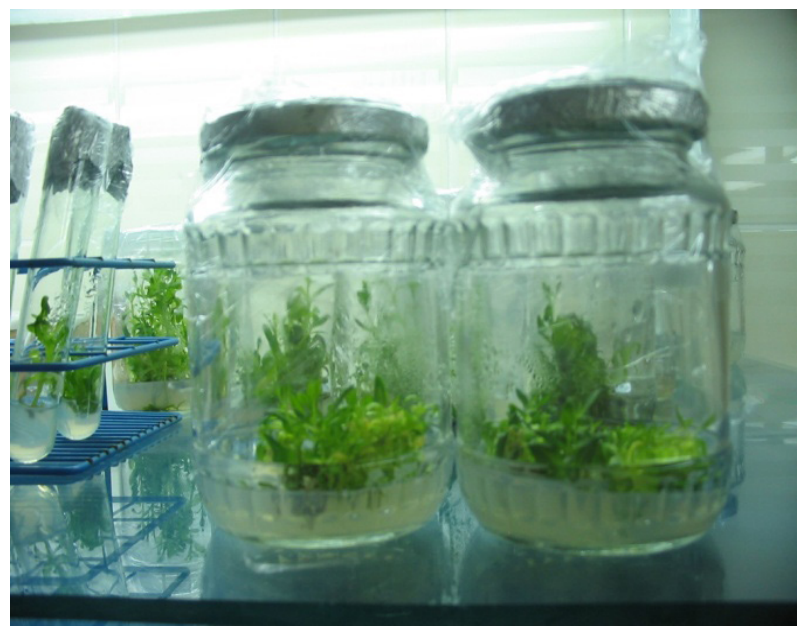

Fig.1. Shoots on $\mathrm{V}_{2}$ medium supplemented with $1.0 \mathrm{mg} 1^{-1} \mathrm{BAP}$ (source: original)

Analyzing the influence of Lisianthus hybrids and the culture media on the number of shoots produced by micropropagation, the data obtained is presented in Tab 1. Concerning this character both variants (culture medium and the hybrids used) had significant effects. The highest number of shoots per explant was obtained in hybrid 'Mirage Pastel Pink' (6.91) and the lowest number of shoots for 'Echo Lavender' (2.5).

The influence of culture medium on the number of shoots produced by in vitro culture is also significant. A great number of shoots were obtained on $V_{2}$ medium supplemented with $1.0 \mathrm{mg}$ $1^{-1} \mathrm{BAP}$. The strongest influence on the number of shoots had the culture medium (Fig. 1).

Interaction between the two factors (hybrid and culture medium), shows significant differences between variants. The hybrid 'Mirage Pastel Pink' generated the highest number of shoots (6.91) on $\mathrm{V}_{2}$, supplemented with $1.0 \mathrm{mg} 1^{-1}$ BAP versus 2.5 shoots obtained for the hybrid 'Echo Lavender', on variant $\mathrm{V}_{1}$ supplemented with TDZ $\left(0.5 \mathrm{mg}^{1-1}\right)$. Other authors reported the highest shoot number of 2.62 per lisianthus explant (Esizad et al., 2012) or 2.68 (Kaviani, 2014) on MS medium fortified with $1 \mathrm{mg} 1^{-1} \mathrm{KIN}$ without NAA, while other studies report the maximum of 5.80 shoots per explant obtained on medium containing $0.1 \mathrm{mg} 1^{-1} \mathrm{BA}$ along with $0.2 \mathrm{mg}^{-1} \mathrm{NAA}$ (Kaviani et al., 2014). It can be noted that the results obtained for 'Mirage Pastel Pink' in the present study on $\mathrm{V}_{1}$ medium, exceeds the results of these three sources.

\section{Length of shoots}

Table 2 summarizes the experimental results on the influence of culture medium, the hybrid 
Tab. 2. Effects of culture medium $(\mathrm{M})$, hybrid $(\mathrm{H})$ and their interaction $(\mathrm{M} \times \mathrm{H})$ upon shoots length $(\mathrm{cm})$ of in vitro propagated lisianthus hybrids

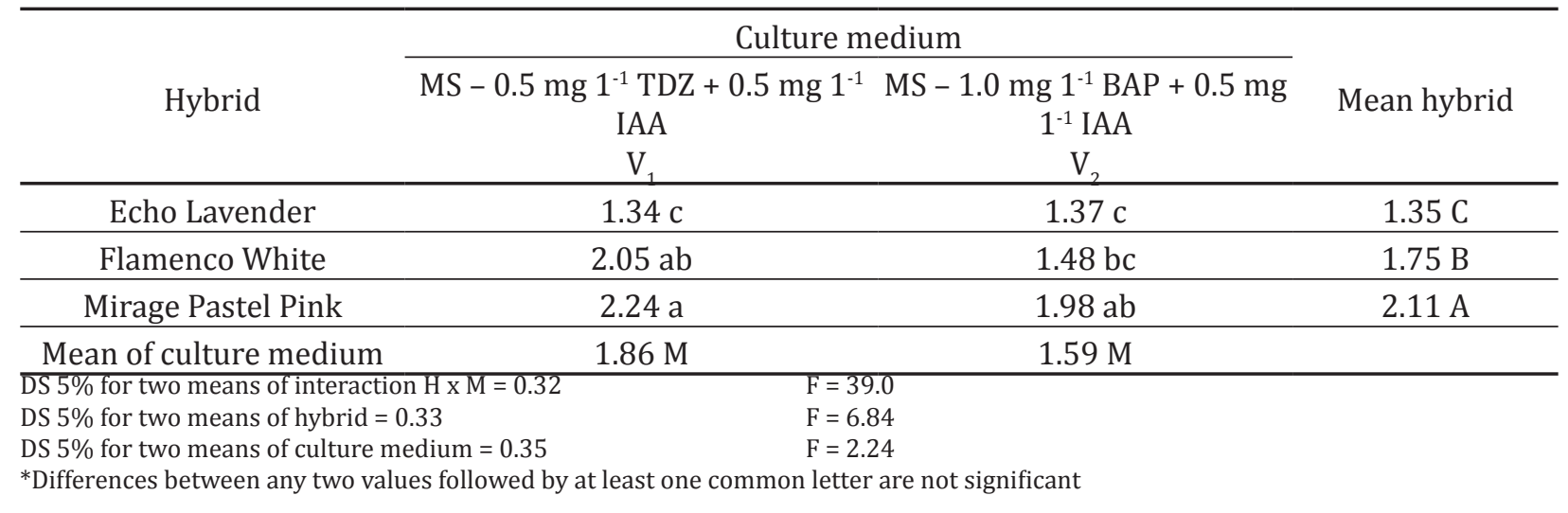

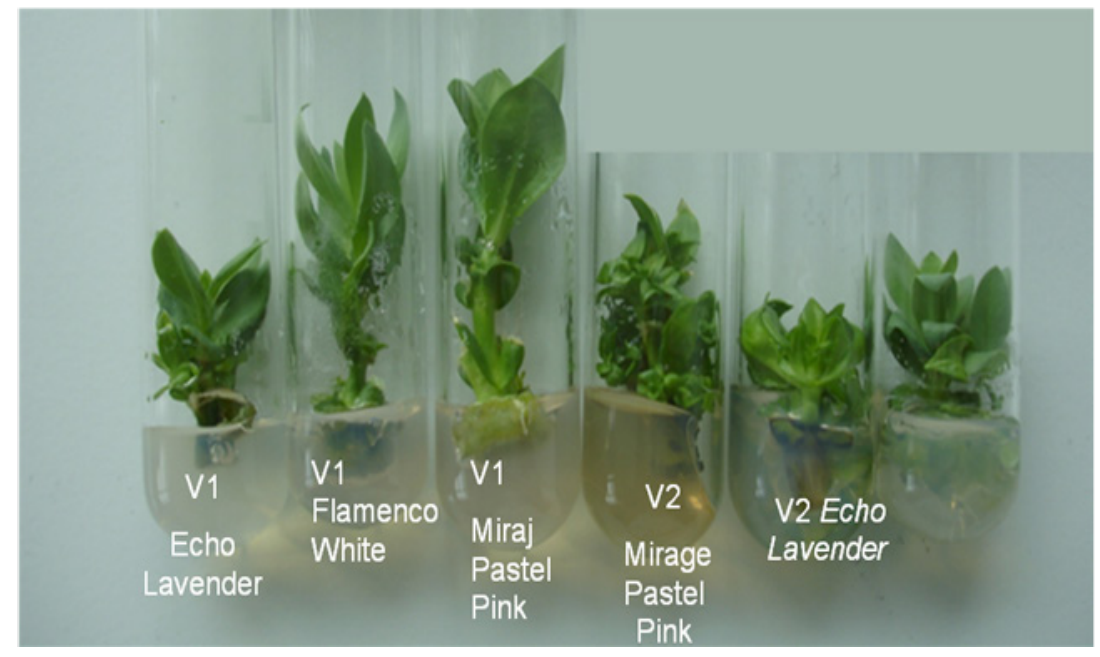

Fig. 2. Shoot length for two variants of culture medium (source: original)

and the interaction of these two factors ( $\mathrm{M} \times \mathrm{H}$ ) on shoots length. The data obtained revealed that there are significant differences between the three hybrids analyzed.

The hybrid that generated the longest shoots was 'Mirage Pastel Pink', with an average length of shoots $(2.11 \mathrm{~cm})$, followed by the hybrid 'Flamenco White' $(1.75 \mathrm{~cm})$. Culture medium had a non significant influence on the length of shoots.

In case of the interaction between hybrid and culture medium $(\mathrm{H} \mathrm{x} \mathrm{M})$ it was observed that there are significant differences between hybrids as follows: the longest shoots were recorded for 'Mirage Pastel Pink' hybrid on $\mathrm{V}_{1}$ culture medium (0.5 mg $\left.1^{-1} \mathrm{TDZ}\right)(2.24 \mathrm{~cm})$ compared to the hybrid 'Echo Lavender' on $\mathrm{V}_{1}$ medium (with 1.0 mg $1^{-1}$ BAP) which had the shortest shoots (1.34 $\mathrm{cm}$ ) (Fig. 2). Some authors obtained the best shoot length per Lisianthus explant of $2.058 \mathrm{~cm}$
(Esizad et al., 2012) and $2.158 \mathrm{~cm}$ (Kaviani 2014) on MS medium supplemented with $1 \mathrm{mg} 1^{-1} \mathrm{KIN}$ without NAA while others (Kaviani et al. 2014) obtained similar maximum shoot lengths of 2.07 $\mathrm{cm}$ on medium supplemented with $0.1 \mathrm{mg}^{-1}$ BA without NAA. But as it can be observed the results obtained in the present study for 'Mirage Pastel Pink' on $\mathrm{V}_{1}$ culture medium is similar and only very slightly exceeding their results.

The data obtained concerning the length of shoots using cytokinin (TDZ) indicates that the callus formation on the base of the shoots prevented the formation of a greater number of shoots. Thus, in this variant the shoots were produced fewer but had higher lengths than when benzyl-amino-purine (BAP) was used. 
Tab. 3. Effects of culture medium (M), hybrid (H) and their interaction ( $\mathrm{M} \times \mathrm{H}$ ) upon the number of roots for in vitro propagated Lisianthus

\begin{tabular}{|c|c|c|c|}
\hline \multirow[b]{2}{*}{ Hybrid } & \multicolumn{2}{|c|}{ Culture medium } & \multirow[b]{2}{*}{ Mean hybrid } \\
\hline & $\begin{array}{c}\text { MS - } 0.5 \mathrm{mg}^{-1} \mathrm{IBA} \\
\mathrm{V}_{1}\end{array}$ & $\begin{array}{c}\text { MS - } 1.5 \mathrm{mg}^{-1} \mathrm{IBA} \\
\mathrm{V}_{2} \\
\end{array}$ & \\
\hline Echo Lavender & $8.2 \mathrm{a}$ & $10.7 \mathrm{a}$ & $9.5 \mathrm{C}$ \\
\hline Flamenco White & $17.8 \mathrm{~b}$ & $38.2 \mathrm{~d}$ & $28.0 \mathrm{~B}$ \\
\hline Mirage Pastel Pink & $30.4 \mathrm{c}$ & $57.4 \mathrm{e}$ & $43.9 \mathrm{~A}$ \\
\hline Mean of culture medium & $18.8 \mathrm{M}$ & $35.43 \mathrm{~N}$ & \\
\hline \multicolumn{3}{|c|}{$\begin{array}{ll}\text { DS } 5 \% \text { for two means of interaction } \mathrm{Mx} \mathrm{H}=2.82-3.07 & \mathrm{~F}=3.88\end{array}$} & \\
\hline \multicolumn{3}{|c|}{ DS $5 \%$ for two means of hybrid $=1.99-2.08$} & \\
\hline \multicolumn{2}{|c|}{ DS $5 \%$ for two means of culture medium $=2.07$} & $\mathrm{~F}=4.75$ & \\
\hline
\end{tabular}

\section{Rooting of regenerated shoots}

For induction of rooting, seedlings were transferred to MS medium supplemented with auxine, respectively indole-butyric acid (IBA) with 0.5 and $1.5 \mathrm{mg}^{-1}$ concentration (Tab. 3). Roots started to appear about three weeks after inoculation.

Rooting response of the explants was higher in the presence of $1.5 \mathrm{mg}^{-1} \mathrm{AIB}$ (57.4) for 'Mirage Pastel Pink', while other studies revealed the favorable effect of NAA for root formation (Esizad et al., 2012, Mousavi et al., 2012, Akbari et al., 2014, Kaviani, 2014). However, while Esizad et al., (2012) obtained the best results with $0.5 \mathrm{mg} 1^{-1}$ NAA on MS medium similar with Kaviani (2014), Mousavi et al. (2012) observed the highest number of roots per shoot of Eustoma grandiflorum on B5 (Gamborg) medium supplemented with $1.5 \mathrm{mg}$ $1^{-1}$ NAA. Moreover, other studies conducted for lisianthus report that the largest number of roots and root length were produced on $0.2 \mathrm{mg} 1^{-1} \mathrm{NAA}$ without BA as well as on $0.2 \mathrm{mg} 1^{-1} \mathrm{BA}$ plus $0.2 \mathrm{mg}$ $1^{-1}$ NAA (Kaviani et al., 2014).

There are several other reports on suitability of NAA for rooting of ornamental species (Kharrazi et al., 2011, Mii et al., 1990, IIahi et al., 1995). Ali et al. (2008) found that among the various concentrations of NAA and IBA, the best rooting response was obtained on MS medium containing $1 \mathrm{mg} 1^{-1} \mathrm{NAA}$.

Regarding the rhizogenesis in dark conditions for lisianthus, the results obtained by Rezaee et al. (2012) in their comparative study of different culture media indicate that the most rapid root formation probably occurs in LS medium, compared to B5 and MS medium.
The type and concentration of auxins used influenced both the number and length of the roots. These observations confirmed similar results obtained by other authors on various cultivars of carnation when different kinds of auxins were used (Mahdyech et al., 2011). Also, there are several reports on suitability of auxinfree medium for rooting of carnation cultivars (Mii et al., 1990, IIahi et al., 1995).

After formation of the root system, plantlets obtained were transferred ex vitro on peat substrate (Fig. 3). But other authors successfully used a mixture of burned-rice husk and organic manure 1:1 (Winarto et al., 2015) or peat and perlite 1:1 (Esizad et al., 2012) for acclimatization of lisianthus regenerated plantlets.

Auxin has a major role in root induction through its effect on the first division of cell which forms root initials (Farooq et al., 2008). Salehi (2008) found that the rooting process of carnations is highly genotype dependent and there is a great range of variation among carnation cultivars and this cultivars present different requirement for in vitro plant growth regulators. Also, he underline that the general medium for rooting of different carnation cultivars, is not possible. Results of the studied conducted by Salehi (2008) showed interesting results. Plantlets with higher root numbers have the lower root lengths. But the results obtained in the current study did not confirm this negative connection for lisianthus. In the researchers conducted by Ali et al. (2008) it was found that among the various concentrations of NAA and IBA, the best rooting response were obtained on MS medium containing $1 \mathrm{mg} 1^{-1} \mathrm{NAA}$. Also, there are several reports on suitability of auxin-free medium for 


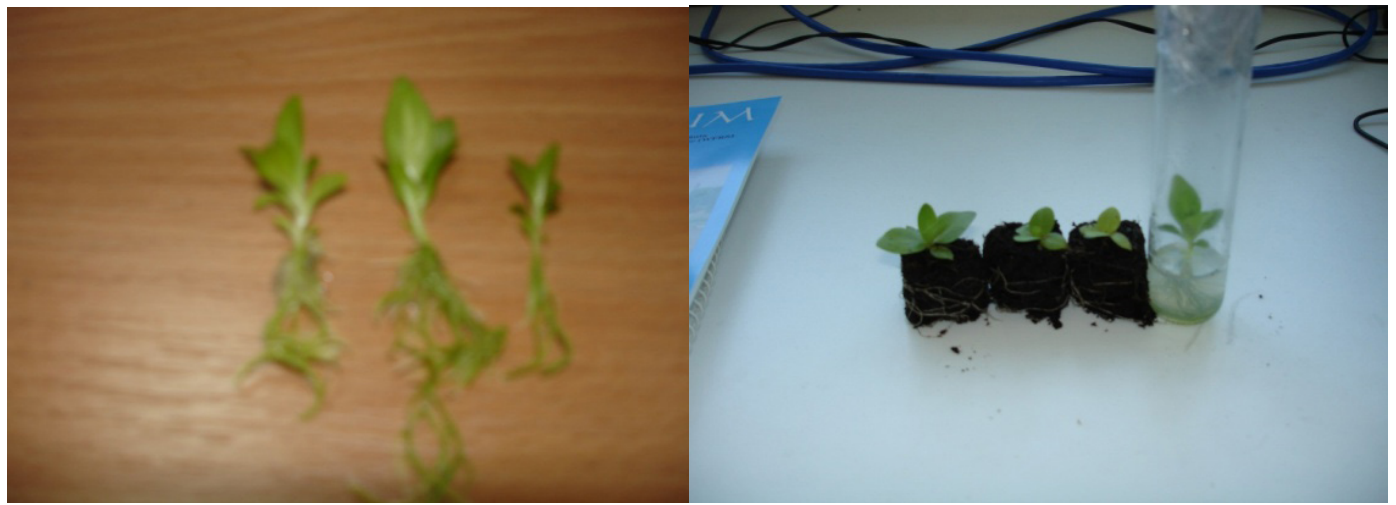

Fig. 3. Plantlets prepared for acclimatization and planted in substrate (source: original)

rooting of carnation cultivars (Mii et al., 1990, IIahi et al., 1995). Notwithstanding these reports, in the current studies it was observed that auxinfree medium did not determine a good rooting percentage, maybe due to genotype differences. The obtained results are in accordance with the findings of Cuzzuol et al. (1996) and Jagannatha et al. (2001).

The rooted Lisianthus plantlets obtained in this study were successfully acclimatized and transferred to greenhouse where they displayed normal growth and a survival rate of $90 \%$. Recent authors report similar survival rates of 90\% (Winarto et al., 2015) for lisianthus 'White Lavender' or of $98 \%$ in the study conducted by Kaviani et al. (2014).

\section{CONCLUSION}

Based on the results of the current study can be concluded that several factors as hybrid, the type and concentration of growth regulators can influence favorable the micropropagation and the rooting of lisianthus. Obtained result shown that there was significant differences in the average number of regenerated shoots between the cultivars, with the hybrid 'Mirage Pastel Pink' producing more regenerated shoots than 'Echo Lavender' and 'Flamenco White'.

It can be concluded that the use of BAP resulted in a significantly higher shoot multiplication compared to TDZ. Application of BAP in the medium compared with TDZ stimulates also the length of plantlets.

Rooting of regenerated shoots was depended of genotype while the best rooting response took place for $1.5 \mathrm{mg}^{-1}$ of IBA auxin. The rooted plantlets were successfully acclimatized and transferred to greenhouse (with a $90 \%$ success), where they displayed normal growth.

Concentration of $0.5 \mathrm{mg}^{-1} \mathrm{TDZ}$, induced the formation of a smaller number of shoots with different lengths due to stimulation of callus formation.

The high rates of proliferation and good survival percentage after acclimatization make these results an excellent choice for large scale propagation of lisianthus hybrids and the viable alternative for micropropagation in order to promote this ornamental plant for green houses in Romania. These methods may be successful for the large scale production.

\section{REFERENCES}

1. Ali A, Afrasiab H, Naz S, Rauf M, and Iqhbal J (2008). An efficient protocol for in vitro propagation of carnation (Dianthus caryophyllus L.). Pak J Bot., 40:111-121.

2. Akbari H, Reyhaneh P, Narges K (2014). Evaluating the micropropagation of Lisianthus (Eustoma grandiflora L.) as an important ornamental. Indian Journal of Fundamental and Applied Life Sciences Vol 4 (2):596602/ISSN: 2231-6345.

3. Esizad SG, Kaviani B, Alireza T, Sahar BZ (2012). Micropropagation of Lisianthus (Eustoma grandiflorum) an ornamental plant. Plant Omics Journal 5(3):314-319.

4. Furukawa H, Matusbara C, Shigematsu N (1990). Shoot regeneration from the roots of priaire gentian (Eustoma grandiflorum (Griseb.,) Schinners). Plant Tiss Cult Letters 7 (1): 11-13.

5. Harbaugh BK (2006). Lisianthus, Eustoma grandiflorum. In: Anderson NO (ed), Flower Breeding and Genetics, Springer, Netherlands, pp. 645-663.

6. IIahi I, Aziz F, and Jabeen M (1995). Tissue culture studies for micropropagation of carnation (Dianthus caryophyllus L.). Pak J Bot 27:411-415.

7. Kaviani B, Forouzan Z, Sahar BZ, Alireza T, Ali MT (2014). In vitro flowering and micropropagation of Lisianthus (Eustoma grandiflorum) in response to plant growth 
regulators (NAA and BA). Acta Sci Pol Hortorum Cultus 13(4):145-155.

8. KavianiB(2014). Micropropagation oftenweeks (Matthiola incana) and lisianthus (Eustoma grandiflorum) (two ornamental plants) by using kinetin (Kin), naphthalene acetic acid (NAA) and 2,4-dichlorophenoxyacetic acid (2,4 D). Acta Sci Pol Hortorum Cultus 13(1):141-154.

9. Mahdiyeh K, Hossein N, Ali T, Abdolreza B, Ahmad S (2011). In vitro culture of carnation (Dianthus caryophyllus L.) focusing on the problem of vitrification. J Biol Environ Sci 5(13):1-6.

10. Mii M, Buiatti M, Gimelli F (1990). Carnation, In: Ammirato PV, Evans DA, Sharp WR, Bjaja YPS (ed) Handbook of Plant Cell Culture. McGraw-Hill pub. Co., New York, USA. pp. 284-318.
11. Mousavi ES, Behbahani M, Hadavi E, Miri SM, Karimi N (2012). Plant Regeneration in Eustoma Grandiflorum from axillaries buds (Gentianaceae). Trakia Journal of Sciences Vol 10 No 2:75-78.

12. Murashige T, Skoog F (1962). A revised medium for rapid growth and bioassays with tobacco tissue culture. Physiol Plant 15:473-497.

13. Rezaee F, Faezeh G, Laleh YB (2012). Micropropagation of Lisianthus (Eustoma grandiflorum L.) from different explants to flowering onset. Iranian Journal of Plant Physiology Vol (3), No (1).

14. Toma F (2009). Floriculture and Floral Art. In vol II, Invel Multimedia, Bucharest, pp. 129.

15. Winarto B, Fitri R, Anggraeni SS, Jaime ATS (2015). Leafderived organogenesis in vitro for mass propagation of lisianthus Eustoma grandiflorum (Raf.) Shinn. Emir J Food Agric 2015; 27(6): 495-501. 